\title{
SIMULATION IN NURSING PRACTICE: THE IMPACT ON PATIENT CARE Hanan Mohammed Mohammed ${ }^{1}$, Manal Salah Hassan ${ }^{2}$ \\ 1Assistant Professor of Medical Surgical Nursing Department, Faculty of Nursing, Ain Shams University \\ 2Professor of Medical Surgical Nursing Department, Faculty of Nursing, Ain Shams University \\ E-mail of the corresponding author hanan.t2004@yahoo.com
}

\begin{abstract}
:
Simulation has a well-known history in the military, nuclear power, and aviation. It is also a recommended teaching and learning strategy supported by several landmark studies. Although in the past 20 years simulation has become more integrated into the education of nurses and physicians, it has not been as well integrated into the development of skills for practicing nurses. This article will provide an overview of simulation techniques and uses and review of selected simulation research. Despite recommendations for using simulation and growing integration of simulation into education, we still lack empirical evidence of its impact on patient outcomes. Our discussion provides a review of the current uses of simulation in the nursing practice environment with several exemplars and offers recommendations to develop a simulation program.
\end{abstract}

\section{Keywords:}

\section{Introduction:}

Simulation has a well-known history in the military, nuclear power, and aviation industries. The aviation industry uses flight simulators for pilot training and has developed Crew Resource Management for the training of non-technical skills for flight crews. The nuclear power industry trains for disasters, and the military has used war games and simulation very successfully in their training programs [1]. Simulation in the area of medicine and nursing has become an important part of the education of students and practicing healthcare providers. Many institutions have made recommendations around the use of simulation in healthcare training. The Institute of Medicine's report on nursing work environments recommends simulation as a method to support nurses in the ongoing acquisition of knowledge and skills [2].

Simulation is mentioned as a strategy to support inter-professional education. The
Carnegie Foundation for the Advancement of Teaching report; Educating Nurses, highlights simulation as an effective strategy for the education of nursing students. Simulation has become more integrated into the education of nurses and physicians in the past 20 years, but is not fully integrated into the development of skills for practicing nurses. Despite recommendations for use of simulation, and growing integration of simulation into education, empirical evidence for the impact of simulation on patient outcomes is still underdeveloped [3]. This article will provide an overview of simulation techniques and uses; review selected emerging research linking simulation to patient outcomes; discuss current uses of simulation by practicing nurses; and recommend strategies to develop a simulation program. 


\section{Overview of Simulation}

Simulation is a technique, not a technology, to replace or amplify real experiences with guided experiences, often immersive in nature, that evoke or replicate substantial aspects of the real world in a fully interactive fashion. As the science of simulation grows, there is ongoing work towards a common guiding taxonomy and set of practices; however, there is not currently one universally accepted framework or theory in use. One common framework used in nursing education is The Nursing Education Simulation Framework. Medicine and nursing have also used the Event Based Approach to Training to guide simulation development [4]. The International Nursing Association for Clinical Table 1. Simulation Definitions
Simulation and Learning (INACSL) has developed a common set of definitions for use in simulation as well as a set of 7 Best Practice Standards [5].

Even though there is not a common simulation framework, most simulations follow a similar design. There is usually some pre-work, or preparation learning, by the participant before the simulation. This is followed by the implementation of the simulation, which is subsequently followed by a debriefing session. Debriefings are generally conducted as a reflective learning experience in which participants review their performance in the simulation and the facilitator provides additional feedback. Commonly used terminology in simulation is highlighted in Table 1 [6].

\begin{tabular}{|l|l|}
\hline \multicolumn{1}{|c|}{ Term } & \multicolumn{1}{c|}{ Description } \\
\hline Clinical Scenario & $\begin{array}{l}\text { *The plan of an expected and potential course of events } \\
\text { for a simulated clinical experience. }\end{array}$ \\
\hline Debriefing & $\begin{array}{l}\text { *An activity that follows a simulation experience and } \\
\text { that is led by a facilitator. }\end{array}$ \\
\hline Facilitator & $\begin{array}{l}\text { *An individual who guides and supports participants } \\
\text { toward understanding and achieving objectives. }\end{array}$ \\
\hline Fidelity & $\begin{array}{l}\text { *Believability, or the degree to which a simulated } \\
\text { experience approaches reality; as fidelity increases, } \\
\text { realism increases. }\end{array}$ \\
\hline High-Fidelity Simulations & Simulations that utilize computerized manikins \\
\hline Mid-Fidelity Simulations & $\begin{array}{l}\text { Simulations that utilize standardized patients, computer } \\
\text { programs or video games }\end{array}$ \\
\hline Low-Fidelity Simulations & $\begin{array}{l}\text { Simulations that use role play, non-computerized } \\
\text { manikins or task- trainers }\end{array}$ \\
\hline Task-Trainers & $\begin{array}{l}\text { Simulators that are used to practice a skill such as an IV } \\
\text { arm that is used to practice IV insertions skills }\end{array}$ \\
\hline In-situ simulation & $\begin{array}{l}\text { This refers to bringing the simulation (and simulator) to } \\
\text { the site where the learner is practicing. This could occur } \\
\text { in an ER trauma bay or surgical suite. }\end{array}$ \\
\hline
\end{tabular}

*These definitions are directly from the INACSL Standards of Best Practice: Simulation

\section{Review of Selected Simulation} Research

This article is not an exhaustive review of the literature on simulation or the impact of simulation on patient outcomes, but
(Shea-Lewis, A. (2009)) [7].

rather considers selected publications to direct readers to emerging evidence and provide some context for the later discussion about simulation in nursing practice. There are several review articles 
the reader may want to consider. Eighteen articles were reviewed and contained measures of both technical and nontechnical skills. There are some articles that have included nursing staff in hospital settings that have also measured patient outcomes. Few studies measured the impact of nursing alone on patient outcomes. Schubert, C. R. (2012) [8] studied the effectiveness of high-fidelity simulation on medical-surgical nurses' ability to recognize and respond to clinical emergencies. This study was a self-report of the participants' (38 registered nurses) ability to respond to emergencies after they received simulation training. Schmidt, (2013) [9] reported on a simulation intervention to improve registered nurse's triage ability in the emergency department. The six nurses who completed the simulation and didactic training showed improvement in their ability to accurately triage patients as measured through chart review of triage documentation. This brief review of the literature around simulation effectiveness demonstrates the extension of inquiry beyond the nursing education environment to consider how the use of simulation may impact patient outcomes. The next section will highlight some examples of how nurses are using simulation in the practice environment.

\section{Use of Simulation in the Nursing} Practice Environment

Simulation has been used in a variety of ways in the practice setting [10]. At Massachusetts General Hospital in Boston, a simulation program was developed to target both nurses and the interdisciplinary team. They redesigned a classroom into a simulation room and purchased a

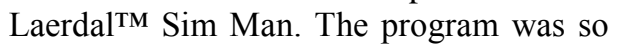
successful that they were able to obtain funding for a simulation center and capital funding for additional simulators, which included the addition of infant and birthing simulators. They currently have seven simulation programs, five of which are focused on nurses with varying levels of experience, including new graduates, and different types of work environments (e.g. critical care, acute care). Each program includes several scenarios, lecture/practice, and debriefing. The scenarios include respiratory arrest, asthma, post-partum hemorrhage, and acute changes in mental status [11].

Some hospitals have included simulation as part of their critical care orientation. Georgetown University in Washington, DC, created a simulation program when it opened a new cardiac surgery unit and developed scenarios to focus on highfrequency, high-acuity situations [12]. In Canada, a Critical Care e-Learning program was developed that uses simulation as part of a three-part approach, which also included on-line courses and a mentored clinical experience. Participants in this program completed 39 hours of high-fidelity simulation training. The simulations were developed using a scaffolding approach; this technique starts with learning stations, minor cases and then major cases. The major cases included cardiogenic shock, acute respiratory distress syndrome, abdominal aortic aneurysm, and septic shock [9]. Simulation cases ran for 20 to 25 minutes followed by a 30-minute debriefing. The simulation training was offered through a partnership with nine universities and colleges and included both weekend and weeklong formats. Participants were evaluated using a pre/post knowledge test for each learning station. Feedback from participants consistently described the benefits such as increased confidence, engagement, and active learning [13].

Acute stroke care has become a priority in healthcare in many countries, including the United Kingdom [2]. Providers in one London hospital used simulation with a goal to improve management of stroke patients in hyper-acute stroke units. A pilot stroke simulation study day was 
developed and included simulations on post-thrombolysis, raised intracranial pressure, seizures, and accelerated hypertension. The debriefing sessions focused in part on evaluating nontechnical skills, such as teamwork, to see what improvements could be made [13]. Pre and post questionnaires showed a selfreported improvement in leadership, communication skills, and confidence in managing hyper-acute stroke clinical situations in six of seven respondents. In another project conducted with stroke unit nurses, high-fidelity simulation was incorporated into stroke unit education for registered nurses during their orientation to the acute stroke unit at a large tertiary care center. Nurses participated in three scenarios based on areas they felt were important to providing successful care for stroke unit patients. Overall evaluation by nursing staff after the simulation and debriefing was very positive; $100 \%$ of the participants ranked the effectiveness of the simulations as excellent [14].

\section{Exemplars of Simulation in the Practice Area}

Even the brief review above provides multiple examples of simulation in a variety of practice settings using several different simulation techniques. A variety of simulation methodologies can be used for education and training of practicing nurses [15]. This can include high and low fidelity mannequins, virtual environments, and unfolding video case simulations. This section will provide some exemplars from the authors' own work in which a range of simulation techniques have addressed various areas, all with the goal of improving patient safety and outcomes[16].

\subsection{Ambulatory Care}

A multi-faceted educational approach aimed at improving nurse competencies in diabetes self-management was initiated with 21 ambulatory care nurses. Simulations were conducted in the virtual environment, Second Life ${ }^{\mathrm{TM}}$, to allow nurses an opportunity to practice empowerment-based skills in the context of Type 2 diabetes [6]. The scenarios required the nurses to interact with three patients: one patient identified as 'noncompliant;' one patient who required education in medication management; and one patient who had extensive psychosocial needs that created barriers to effectively manage the diabetes. Each scenario required nurses to identify underlying issues for the patient, collaboratively create mutual goals, and consider next steps for the patient [17].

\subsection{High-Fidelity Simulation}

In an adult unit, simulation was used to support education aimed at improving the nurse's ability to recognize and manage the deteriorating patient. Three unfolding scenarios were developed using highfidelity simulation. The simulation scenarios focused on acute respiratory failure requiring intubation; atrial fibrillation requiring treatment; and mental status changes. These were areas of high volume on the unit and important for overall patient care. In an intensive care unit, several simulation scenarios were developed and implemented to support nurses who needed to learn a new procedure using complex technical equipment for very critically ill patients. The focus here was on troubleshooting alarms with the equipment and managing patient responses to therapy [18].

5.3. Video Unfolding Case Simulations

In an effort to improve the overall effectiveness of the annual competency blitz at a large Midwestern health system, educators and faculty collaborated to develop an interactive delivery method [19]. This included two 20 minute simulation videos based upon nurse sensitive quality indicators, including restraint alternatives; pressure ulcer prevention; fall and catheter-associated urinary tract infection (CAUTI) 
prevention; infection control; venous thromboembolism/deep vein thrombosis (VTEDVT) prophylaxis; and stroke recognition and intervention [20,21]. Participants were placed into groups of 8 to 10 staff where the videos were reviewed and discussed. Throughout each video, there were opportunities to pause and ask debriefing questions related to content. For example, one of the videos showed a patient who was placed in restraints inappropriately. The discussion centered on how the use was inappropriate and possible alternatives to restraints $[22,23]$.

\section{Conclusion}

Simulation has demonstrated effectiveness as a method to train practicing nurses for new procedures, communication processes, and both skill based and nonskill based techniques. This can be done using a variety of methodologies, ranging from simple role-play to use of highfidelity and virtual simulators. The above described exemplars provide an overview of the variety of ways simulation can be integrated into staff nurses' training.

Simulation can provide an effective mechanism for improving competency in a given area. For example, if a manager reviews unit data and notes an increase in response time to codes (e.g. early identification of deteriorating patients is not occurring), simulation may provide an opportunity for the team to 'practice' assessment and subsequent treatment of the deteriorating patient. Similarly, unit leadership may note a reduction in collaboration occurring among the multidisciplinary team. Simulation scenarios requiring communication among the team may assist in improving collaboration and subsequent patient care. Simulation could also be included in a new orientation program, requiring new orientees to participate in standardized simulations that depict issues most experienced by a given unit's patient population.
Simulation can also be considered as an evaluation method. For example, new hires could be required to successfully complete a series of skill-based simulations (e.g. mastery of suctioning tracheostomies, assessing chest tubes, IV insertion) prior to completing orientation. Simulation could also be used to ensure annual competencies (as described in the unfolding case exemplar) or to remediate poor performing employees.

In addition to its usefulness in nursing education, simulation provides a suitable methodology for deliberately performing skills necessary to be an effective practicing nurse. Many of these simulations can be done without a costly, high fidelity mannequin. One must only consider the overall purpose of the simulation and be creative.

\section{References}

1.Wolf, L. (2008). The use of human patient simulation in ED triage training can improve nursing confidence and patient outcomes. Journal of Emergency Nursing, 34(2), 169. doi: 10.1016/j.jen.2007.11.005

2.Wayne, D. B., Didwania, A., Feinglass, J., Fudala, M. J., Barsuk, J. H., \& McGaghie, W. C. (2008). Simulationbased education improves quality of care during cardiac arrest team responses at an academic teaching hospital: A case-control study. Chest, 133(1), 56-61. doi: 10.1378/chest.070131

3.Tschannen, D., Aebersold, M., McLaughlin, E., Bowen, J., \& Fairchild, J. (2012) Use of virtual simulations for improving knowledge transfer among baccalaureate nursing students. Journal of Nursing Education and Practice, 2(3), 15-24. doi: 10.5430/jnep.v2n3p15.

4.Theilen, U., Leonard, P., Jones, P., Ardill, R., Weitz, J., Agrawal, D., \& Simpson, D. (2013; 2012). Regular in situ simulation training of paediatric 
medical emergency team improves hospital response to deteriorating patients. Resuscitation, 84(2), 218. doi: 10.1016/j.resuscitation.2012.06.027

5.Stirling, K., Smith, G., \& Hogg, G. (2012). The benefits of a ward simulation exercise as a learning experience. British Journal of Nursing (Mark Allen Publishing), 21(2), 116-8, 120-2.

6.Shearer, J. E. (2013). High-fidelity simulation and safety: An integrative review. The Journal of Nursing Education, 52(1), 39-45. doi: 10.3928/01484834-20121121-01; 10.3928/01484834-20121121-01

7.Shea-Lewis, A. (2009). Teamwork: Crew resource management in a community hospital. Journal for Healthcare Quality: Official Publication of the National Association for Healthcare Quality, 31(5), 14.

8.Schubert, C. R. (2012). Effect of simulation on nursing knowledge and critical thinking in failure to rescue events. Journal of Continuing Education in Nursing, 43(10), 467-471. doi: 10.3928/00220124-20120904-27; 10.3928/00220124-20120904-27

9.Schmidt, E., Goldhaber-Fiebert, S. N., Ho, L. A., \& McDonald, K. M. (2013). Simulation exercises as a patient safety strategy: A systematic review. Annals of Internal Medicine, $158(5 \mathrm{Pt} 2), 426$.

10.Rosen, M. A., Salas, E., Wu, T. S., Silvestri, S., Lazzara, E. H., Lyons, R., . . . King, H. B. (2008). Promoting teamwork: An event-based approach to simulation-based teamwork training for emergency medicine residents. Academic Emergency Medicine: Official Journal of the Society for Academic Emergency Medicine, 15(11), 1190-1198. doi: 10.1111/j.1553-2712.2008.00180.x

11.Roots, A., Thomas, L., Jaye, P., \& Birns, J. (2011). Simulation training for hyperacute stroke unit nurses.
British Journal of Nursing (Mark Allen Publishing), 20(21), 1352-1356.

12.Riley, W., Davis, S., Miller, K., Hansen, H., Sainfort, F., \& Sweet, R. (2011). Didactic and simulation nontechnical skills team training to improve perinatal patient outcomes in a community hospital. Joint Commission Journal on Quality and Patient Safety / Joint Commission Resources, 37(8), 357.

13.Rauen, C. (2004). Simulation as a teaching strategy for nursing education and orientation in cardiac surgery. Critical Care Nurse, 24(3), 46-51.

14.Pilcher, J., Goodall, H., Jensen, C., Huwe, V., Jewell, C., Reynolds, R., \& Karlsen, K. A. (2012). Special focus on simulation: Educational strategies in the NICU: Simulation-based learning: It's not just for NRP. Neonatal Network: NN, 31(5), 281-287. doi: 10.1891/0730-0832.31.5.281; 10.1891/0730-0832.31.5.281

15.Phipps, M. G., Lindquist, D. G., McConaughey, E., O'Brien, J. A., Raker, C. A., \& Paglia, M. J. (2012; 2011). Outcomes from a labor and delivery team training program with simulation component. American Journal of Obstetrics and Gynecology, 206(1), $3 . \quad$ doi: 10.1016/j.ajog.2011.06.046

16.Orledge, J., Phillips, W. J., Murray, W. B., \& Lerant, A. (2012). The use of simulation in healthcare: From systems issues, to team building, to task training, to education and high stakes examinations. Current Opinion in Critical Care, 18(4), 326.

17.National Research Council. (2011). The future of nursing: Leading change, advancing health. Washington, DC: The National Academies Press. Retrieved from www.nap.edu/catalog.php?record id=1 $\underline{2956}$ 
18.Nagle, B., McHale, J., Alexander, G., \& French, B. (2009). Incorporating scenario-based simulation into a hospital nursing education program. Journal of Continuing Education in Nursing, 40(1), 18-27. doi: 10.3928/00220124-20090101-02

19.McGaghie, W. C., Issenberg, S. B., Petrusa, E. R., \& Scalese, R. J. (2010). A critical review of simulation-based medical education research: 20032009. Medical Education, 44(1), 50. doi: $10.1111 / \mathrm{j} .1365-$ 2923.2009.03547.x

20.Lapkin, S., Levett-Jones, T., Bellchambers, H., \& Fernandez, R. (2010). Effectiveness of patient simulation manikins in teaching clinical reasoning skills to undergraduate nursing students: A systematic review. Clinical Simulation in Nursing, 6(6), e207. doi: 10.1016/j.ecns.2010.05.005
21.Kardong-Edgren, S., Hanberg, A., Dodge Ackermann, A., Alinier, G., Anderson, M., Fowler Durham, C., . . . Van Gele, P. (2011). Supplement. Clinical Simulation Nursing, (4S) Supplement, S1-S20.

22. Harder, B. N. (2010). Use of simulation in teaching and learning in health sciences: A systematic review. The Journal of Nursing Education, 49(1), 23. doi: 10.3928/0148483420090828-08

23.Goldsworthy, S. (2012). High fidelity simulation in critical care: A Canadian perspective. Collegian, 19(3), 139-143. 